Background/introduction UK sexual health clinics provide patients with additional confidentiality by having separate patient records systems, and by not routinely communicating with General Practitioners (GPs). However, research into patients' awareness of these policies is limited.

Aim(s)/objectives To assess patients' knowledge and perceptions of additional confidentiality protections in sexual health clinics.

Methods A self-administered anonymous questionnaire (approved by Trust Clinical Governance Committee) was distributed prospectively to 200 patients attending two level 3 UK sexual health clinics.

Results Response rate was 178/200 (89.0\%). 46/178 (25.8\%) patients were aware that sexual health records are kept separately from other medical records, and 89/178 (50.0\%) had never been told how their notes are handled. After learning more about confidentiality protections in sexual health clinics, $47 / 178(26.4 \%)$ reported that they would be more likely to give GP details, 67/178 (37.6\%) to give updated contact details, and $58 / 178(32.6 \%)$ to disclose an accurate sexual history to clinicians. Patients were less confident that their information is kept confidential in the reception area compared to the treatment area $(46.9 \%$ vs $77.3 \%$ feel definitely confident). 16/17 free-text comments received complained about personal information being overheard when registering at the reception.

Discussion/conclusion Sexual health clinics should ensure they provide basic information on additional confidentiality protections, in order to increase the likelihood of patients disclosing intimate information, and ensuring they can be contacted. Efforts to improve patients' perception of confidentiality in reception areas are vital and need to be considered carefully when designing units.

\section{P125 "I GOOGLED IT...": WHAT IS RECOMMENDED ONLINE FOR THE MANAGEMENT OF VULVOVAGINAL CANDIDIASIS?}

Jonathan Shaw*, Orla McQuillan. The Hathersage Integrated Contraception, Sexual Health and HIV Service, Manchester, UK

\subsection{6/sextrans-2016-052718.179}

Background Recently our centre encountered women reporting self-treatment of candidiasis with intravaginal applications of foodstuffs including garlic, vinegar and yoghurt. All patients had a unifying factor of reporting "googling" their therapy.

Aim To establish which candidiasis management strategies female patients are most likely to encounter when searching via Google. Method Search history data was collated from Google Trends to identify the ten most popular search terms related to candidiasis in the UK between 15/03/15-06/03/16. These terms, along with term "thrush", were assessed totalling 11 Google searches. All websites on the initial results page for each search term were accessed to review recommended therapies. Click-through data suggests the vast majority of Google users (>90\%) select their chosen website from this first results page.

Results 116 search results included 97 (83.6\%) advising women about vulvovaginal candidiasis. 96/97 (99\%) recommended imidazole therapy first line, all reassuringly advising against oral therapy in pregnancy. Patients were recommended to seek treatment via a pharmacy $(72,74.2 \%)$ or their GP $(54,55.7 \%)$ rather than attending a genitourinary service $(12,12.2 \%)$. The recommendation of natural yoghurt for symptomatic relief was frequent $(40,41.2 \%)$, more than using emollients or soap substitutes $(27,27.8 \%)$. Unfounded treatments including eating probiotic yoghurts $(9,9.3 \%)$, vinegar $(8,8.2 \%)$, and treatment of sexual partners $(8,8.2 \%)$ were encountered.

Conclusions Sensible evidence-based advice is the most prevalent online for vulvovaginal candidiasis. However a number of poorly evidenced therapies are encouraged. This information should be discussed and appropriately challenged during routine management of vulvovaginal candidiasis.

\section{P126 "WE CARE ABOUT YOUR CARE": A CLIENT DELIVERED REAL TIME AUDIT AND FEEDBACK TOOL OF HOLISTIC CARE FOR MEN WHO HAVE SEX WITH MEN (MSM) ATTENDING SEXUAL HEALTH SERVICES. AN AUDIT AND REAUDIT}

${ }^{1}$ Joseph Withers Green*, ${ }^{2}$ Joycelyn Temu, ${ }^{2}$ Jessica Davies, ${ }^{2}$ John McSorley. ${ }^{1}$ Imperial College London, London, UK; ${ }^{2}$ Patrick Clements Centre, Central Middlesex Hospital, London, UK

\subsection{6/sextrans-2016-052718.180}

Background In 2014 Public Health England produced an action plan to improve the health and well-being of MSM in the UK. We mapped key domains to create a "Checklist for holistic care of MSM" for staff and audited performance (Audit 1). We redesigned the "Checklist" to enable client led audit and feedback in real time, either named or anonymously and re-audited (Audit 2).

Aims To assess the acceptability and impact of a client led realtime audit and feedback tool on the delivery of holistic care to MSM presenting for STI testing within generic sexual health services.

Methods A retrospective electronic patient record (EPR) case note review of consecutive MSM under 27yrs new to the service between January and May 2015 was performed. (Audit 1). We introduced the Client Checklist in August 2015 and re-audited all MSM attendances to February 2016.

Results

Abstract P126 Table 1 Client delivered real time audit in MSM

\begin{tabular}{|c|c|c|c|}
\hline & $\begin{array}{l}\text { Audit } 1 \text { : } \\
\text { HCW Checklist + } \\
\text { Standard EPR }\end{array}$ & $\begin{array}{l}\text { Audit } 2 \text { : } \\
\text { Patient held } \\
\text { Checklist + } \\
\text { HCW Checklist + } \\
\text { Standard EPR }\end{array}$ & $\begin{array}{l}\text { Probability } \\
\text { Value }\end{array}$ \\
\hline Demographics & $\begin{array}{l}41 \text { MSM <27yrs. } \\
1^{\text {st }} \text { visit }\end{array}$ & $\begin{array}{l}207 \text { MSM 15-63 } \\
\text { yrs. New visit }\end{array}$ & \\
\hline Mobile phone number confirmed & $33 / 41(80 \%)$ & 205/207 (99\%) & $p=0.0001$ \\
\hline Email address given & $29 / 41(70 \%)$ & 197/207 (95\%) & $p=0.0001$ \\
\hline How are you? Answer recorded & 0 & 195/207 (94\%) & \\
\hline Family aware of sexuality? & 0 & 199/207 (96\%) & \\
\hline Vaccines offered? & $41 / 41(100 \%)$ & 198/207 (96\%) & $p=0.04$ \\
\hline Alcohol \& Drug history? & $37 / 41(90 \%)$ & 186/207 (90\%) & $p=1$ \\
\hline PEP/PREP awareness recorded? & $26 / 41(63 \%)$ & $183 / 207(88 \%)$ & $p=0.0002$ \\
\hline STI \& HIV retesting organised? & $20 / 41(49 \%)$ & 193/207 (93\%) & $p=0.0001$ \\
\hline Smoking \& Exercise recorded? & 0 & $133 / 207(64 \%)$ & \\
\hline $\begin{array}{l}\text { MSM pack given (website and } \\
\text { support access information) }\end{array}$ & $11 / 41(27 \%)$ & $179 / 207(86 \%)$ & $p=0.0001$ \\
\hline Named feedback given & 0 & 206/207 (99\%) & \\
\hline
\end{tabular}

Conclusion A client led real time audit of care was highly acceptable to clients and staff and was effective in improving the 